\title{
Toward Competitive Employment for Persons with Intellectual and Developmental Disabilities: What Progress Have We Made and Where Do We Need to Go
}

\author{
Paul Wehman \\ Virginia Commonwealth University, paul.wehman@vcuhealth.org \\ Joshua Taylor \\ Virginia Commonwealth University \\ Valerie Brooke \\ Virginia Commonwealth University \\ See next page for additional authors
}

Follow this and additional works at: https://scholarscompass.vcu.edu/pmr_pubs

Part of the Medicine and Health Sciences Commons

(c) SAGE Publications

\section{Downloaded from}

https://scholarscompass.vcu.edu/pmr_pubs/10

This Article is brought to you for free and open access by the Dept. of Physical Medicine and Rehabilitation at VCU Scholars Compass. It has been accepted for inclusion in Physical Medicine and Rehabilitation Publications by an authorized administrator of VCU Scholars Compass. For more information, please contact libcompass@vcu.edu. 


\section{Authors}

Paul Wehman, Joshua Taylor, Valerie Brooke, Lauren Avellone, Holly N. Whittenburg, Whitney Ham, Alissa Molinelli Brooke, and Staci Carr 
Toward Competitive Employment for Persons with Intellectual and Developmental Disabilities:

What Progress Have We Made and Where Do We Need to Go

Paul Wehman ${ }^{1,3}$; Joshua Taylor ${ }^{1,2}$; Valerie Brooke ${ }^{1,2}$; Lauren Avellone ${ }^{1,2}$; Holly Whittenburg

1,2; Whitney Ham ${ }^{1,2}$; Alissa Brooke ${ }^{1,2}$; Staci Carr ${ }^{1,2}$

Virginia Commonwealth University ${ }^{1}$

Rehabilitation Research \& Training Center

Richmond, VA 23284-2011

Virginia Commonwealth University ${ }^{2}$

School of Education

Richmond, VA 23284-2020

Virginia Commonwealth University ${ }^{3}$

Department of Physical Medicine and Rehabilitation

Richmond, VA 23298-3038

\section{Corresponding author:}

Paul Wehman, Ph.D.

Professor, School of Physical Medicine and Rehabilitation

Director, Rehabilitation Research \& Training Center

Virginia Commonwealth University

Box 842011

Richmond, VA 23284-2011

pwehman@vcu.org

Financial Disclosure:

This paper is funded by the National Institute on Disability, Independent Living, and Rehabilitation Research (NIDILRR grant number \#90RT5041). NIDILRR is a Center within the Administration for Community Living (ACL), Department of Health and Human Services (HHS). Virginia Commonwealth University, Rehabilitation Research and Training Center (VCU-RRTC) an equal opportunity/affirmative action institution providing access to education and employment without regard to age, race, color, national origin, gender, religion, sexual orientation, veteran's status, political affiliation, or disability. 


\begin{abstract}
Progress toward competitive and integrated employment (CIE) for people with intellectual and developmental disabilities (I/DD) over the last 40 years has been mixed. Despite evidence showing that supported employment interventions can enable adults with I/DD to effectively get and keep jobs, national rates of integrated employment remain below a third of the working age population (Hiersteiner et al., 2016). Progress is being made to improve these outcomes. Pathways have been identified that lead to CIE through supported employment, customized employment, internship experiences, and postsecondary education (Siperstein, Heyman, \& Stokes, 2014; Wehman, 2011). The recent passage of the Workforce Innovation and Opportunity Act (WIOA) has created fresh momentum and increased the onus on interagency collaboration. This article examines what is known about promoting CIE through these pathways and highlights recommendations for future research and policy change. Recommendations for the future are provide direction toward positive change in CIE into the $21^{\text {st }}$ century. Keywords: Competitive Integrated Employment; Intellectual Disabilities; Developmental Disabilities; Supported Employment; Customized Employment.
\end{abstract}


Toward Competitive Employment for Persons with Intellectual and Developmental Disabilities:

What Progress Have We Made and Where Do We Need to Go

A job is a central pillar of personal identity in American society. Earning a first paycheck is one of the core rites of passage. Establishing and progressing through a career is one of the primary goals of adult life. These facts are no different for Americans with disabilities, yet often adults regarded as having the most significant characteristics are pushed into segregated residential and sheltered work settings (Brown et al., 1999; Siperstein, Parker, \& Drascher, 2013). The current rate of individually integrated paid employment for adults with intellectual and developmental disabilities (I/DD) is less than 10\% (Hiersteiner et al., 2016). Yet people with I/DD can be successfully employed in competitive, integrated positions and substantially increase earnings in comparison to segregated work or day support programs (Butterworth, Christensen, \& Flippo, 2017; Migliore, Timmons, Butterworth, \& Lugas, 2012; Wehman et al., 2014). Moreover, evidence indicates that a majority of individuals with disabilities and their families prefer competitive integrated employment (CIE) to segregated employment or day services (Gilson, Carter, Bumble, \& McMillan, 2018; Siperstein et al., 2014). For youth, adults, and their families, there is reason for optimism and hope with the recent passage of the Workforce Innovations and Opportunities Act of 2014 (WIOA) and commitment of the Department of Justice to close segregated workshops (Carter et al., 2017; Christensen, Richardson, \& Hetherington, 2017; Tucker, Feng, Gruman, \& Crossen, 2017). Additionally, states are increasingly committing to the Employment First initiative, which recognizes CIE as the only acceptable employment goal for individuals with disabilities (APSE, 2017; Butterworth, Christensen, \& Flippo, 2017; Carter et al., 2017). 
Unfortunately, the use of segregated work and non-work day programs continues to grow noticeably faster than participation in competitive employment programming. For example, between 1999 and 2015, the number of individuals with I/DD in segregated day programs grew from 455,824 to 610,188 (33.8\% increase), while CIE rates remained relatively flat with 108,227 and 113,226 respectively (4.6\% increase; Winsor et al., 2017). This is despite substantial efforts in many states and I/DD agencies to systemically transform their day and work programs by promoting community integrated CIE as the first choice (Centers for Medicare and Medicaid Services, 2013). Additionally, the U.S. Department of Justice (DOJ; 2014) is making settlements in different states to extricate individuals with I/DD from sheltered workshops (e.g., Rhode Island, Oregon, Georgia, and Delaware) and support their transition to competitive employment. Early data from Oregon indicates that DOJ efforts to shift funding away from sheltered workshop settings has led to an early increase in CIE (Oregon Department of Human Services, 2018).

Recent research using National Longitudinal Transition Study-2 (NLTS2) data strongly suggest that youth with I/DD who have a paid job while in school are more likely to have employment upon graduation (Carter, Austin, \& Trainor, 2011; 2012; Wehman et al., 2014). However, there is no proof of concept establishing this as an evidence-based practice. In addition, despite the fact that individuals with I/DD clearly indicate they would prefer not to be in a sheltered workshop (Migliore, Grossi, Mark, \& Rogan, 2008), little research specifically examines how individuals with I/DD would prefer to access employment, or in other words, which pathway best suits their goals. In short, there is much yet to learn and the lack of knowledge represents a huge barrier for improving these egregious employment outcomes. 
In this article, we will discuss what we know about supporting the employment of people with more significant disabilities through specific models that serve as pathways to CIE. We will outline what works within these pathways to CIE and highlight remaining barriers to full implementation at an expanded capacity. Finally, we will discuss what we still need to know and recommendations for future research and policy change.

\section{Models \& Pathways to CIE}

Pathways to employment describe the experiences and services that individuals engage in which lead to successful CIE. Given the inconsistent quality of services provided to people with disabilities, it is preferable to specifically focus on models that lead to positive outcomes rather than simply describing all that are offered. It is also important to note that due to the diversity of the population, the type of job, available community and state resources, no one model can possibly serve the workplace support needs of all people with disabilities. However, we do know that several pathways have been shown to lead to preferred employment outcomes. These are distinct from segregated vocational and pre-vocational models, such as sheltered work and day program settings, which have been shown not to lead to CIE (Siperstein et al., 2014). In the following section, we will describe several of these pathways to CIE, including supported employment, customized employment, internships, and college and other post-secondary education options.

\section{Supported Employment}

Since 1980, supported employment has grown and developed into a primary mainstay for those individuals with the most significant disabilities who have not been seen by others as capable of CIE (Bellamy, 1988; Mank, Cioffi, \& Yovanoff, 1998; Rusch \& Braddock, 2004; Wehman, 1981; Wehman, Chan, Ditchman, \& Kang, 2014). Supported employment was clearly 
a dramatic paradigm shift from providing vocational services in day programs and sheltered workshops to ensuring support at a community integrated job site with training and support from a qualified employment specialist. The purpose of supported employment is to support individuals with the most significant disabilities in achieving competitive employment outcomes in integrated work settings (Wehman, Chan, Ditchman, \& Kang, 2014). In order to ensure efficacy, supported employment requires the professional staff providing services to possess a unique set of skills. Staff must know how to help identify meaningful consumer choice, arrange for funding, identify jobs in the community, approach employers, work with concerned parents, help with social security income (SSI) determination issues, arrange transportation, and — most importantly_effectively train clients to achieve required work standards.

Central to the supported employment approach is the process of first securing CIE for an individual and then providing needed support, rather than waiting for "work readiness" to initiate job placement. In other words, supported employment adopts a "place, then train" rather than a “train, then place" approach. Eliminating unnecessary preparatory training enables individuals with disabilities to learn job skills in real work settings as immediately as possible. Nine guiding principles for supported employment have been identified to reflect core values of the approach (Wehman, Revell, \& Brooke, 2003). With supported employment, there is a Presumption of Employment which refers to the right of all individuals to work, regardless of disability. Job matches must meet the definition of Competitive Employment, by occurring within the community and reflecting the local job market. The Self-Determination of job seekers should be honored by enabling them with primary decision making about placement and services in order to achieve the highest level of job satisfaction. Commensurate Wages and Benefits should be provided. This means that offers regarding pay should match those given to 
employees without disabilities performing similar work. Rather than focusing on deficits, individuals with disabilities should be viewed in terms of their positive attributes by Emphasizing Capacity and Capabilities (Wehman, Revell, \& Brooke, 2003).

Implementation of supported employment involves four phases: 1) getting to know the job seeker, 2) job development and matching, 3) training and support, and 4) job retention services (Schall et al., 2015; Wehman et al., 2012). To briefly summarize, an employment specialist first uses a variety of methods including home visits, a review of relevant records, interviews, and situational assessments to better understand the job seeker's strengths, preferences, interests, and needs related to employment. This information is integrated and analyzed in a meaningful way to help inform the job development process. During job development (phase 2), the employment specialist reaches out to community businesses in industries which align with the job seeker's interests. Once hired, on- and off-the-job training and support (phase 3) is provided by the employment specialist to help the individual with a disability learn their job tasks and acclimate to the work environment. Funding for on-the-job services frequently comes from state Vocational Rehabilitation services. The employment specialist will fade their presence over time as the individual becomes competent and independent. Lastly, ongoing services are put in place to promote long term job retention (Schall et al., 2015; Wehman et al., 2012). Typically, an employment specialist will continue to visit the work site and check in with the employee and employer at least monthly. This allows for any emerging problems to be addressed as quickly as possible.

While supported employment is both cost-effective (Cimera, 2012) and an evidencedbased practice producing positive employment outcomes for a wide range of individuals with disabilities (Bond, Drake, \& Becker, 2008; Ottomanelli et al., 2012; Wehman, Targett, West, \& 
Kregel, 2005; Wehman et al., 2014), there are still many factors to consider that affect the quality of services and success of employment outcomes. Practitioners and researchers using supported employment should be mindful of the following issues:

Use with the unintended population. Supported employment was designed specifically for use with individuals who have the most significant disabilities (Wehman et al., 2003). Despite this, it is still used with individuals with less intensive disabilities to secure employment. It is important that supported employment be recognized as a support for those with the most significant needs who have a challenging history of achieving desirable employment outcomes.

Training of employment specialists. Supported employment is only as good as the individuals providing the services. Therefore, it is essential that employment specialists be well trained in the guiding principles of supported employment and able to execute all phases thoroughly and with fidelity. A breakdown at any level can jeopardize immediate or longer term job stability.

Evaluation of demand-side focus. The job development phase in supported employment has many advantages over traditional job searching methods because it allows for the development of a position that is better suited for the job seeker with a disability. However, supported employment is not always implemented with as much focus on the job seeker's interests (supply-side) as the potential business' (demand-side) interests (Chan et al., 2010).

Poor job matches. An expedient job is not the same as the right job. Too often, a job seeker with a disability ends up employed in a readily available position that turns out to be a poor fit. If employment specialists do their research about the job seeker and the business ahead of time, this can be easily avoided. However, being too quick to agree to the terms of a developed position or failing to consider factors beyond the job tasks that might impact 
performance (such as schedule, setting, or social climate) may lead to dissatisfaction by the individual with a disability over time.

Funding. Once an individual with a disability is successfully hired, they may require additional services periodically to help them successfully maintain their job. Such services may include temporary supports to address issues that arise. Turn-over in management or restructuring of a business may result in the employee with the disability needing assistance adjusting to changes. In other situations, the installation of new supports is required as a person's needs related to their disability change over time.

\section{Customized Employment}

Despite decades of evidence showing the efficacy of supported employment for promoting CIE, those outcomes have not been achieved as well for people with the most significant disabilities (Inge, Graham, Brooks-Lane, Wehman, \& Griffin, 2018; Winsor et al., 2017). Developed in 2001 by the U.S. Department of Labor's Office of Disability Employment Policy (2005) to increase employment for potential employees that required additional considerations in order to secure and retain CIE, customized employment is a part of, and extension of, supported employment. As with other types of supported employment, customized employment is designed for those with significant disabilities, and specifically targets adults who would benefit from additional customization of job responsibilities beyond those naturally occurring within the labor market. It is further distinguished by a well-defined discovery process in which the employment specialist and job seeker engage in a process of identifying the individual's strengths, interests, and preferences. The outcome of that process then drives the identification of employment opportunities, where unique job descriptions are created that match both the employer's and employees' needs and interests. 
Despite a limited research base, customized employment has been included as part of the definition of supported employment through the passage of WIOA in 2014. As a result, vocational rehabilitation funding can be used to provide customized employment. While implementation is not yet widespread, many more state VR agencies are now taking steps to incorporate customized employment into service delivery and training processes (Smith, Dillahunt-Aspillaga, \& Kenney, 2015).

WIOA (2014) describes specific steps needed for implementing customized employment, starting with a discovery process and continuing through a development process to initial and ongoing job training and support. The first step involves person-centered exploration of an individual's strengths, preferences, interests, and needs by the employment specialist, though for many candidates of customized employment, this process may involve nonstandard vocational and preference assessments, including interviews with family members and caregivers (Griffin, Hammis, Geary, \& Sullivan, 2008). Based on that information, the employment specialist negotiates with a business to satisfy an existing need through development of a new (and customized) role. There are several ways to create a customized employment job description; those methods are described in 
1.

\section{INSERT TABLE 1 ABOUT HERE}

As evidenced by the diversity of job creation methods, customized employment requires a high level of competence and flexibility on the part of the employment specialist in order to identify employer needs and match them with an individual's competencies and available resources. Additionally, customized employment encompasses both on the job training and supports, some of which may require long-term follow-up with the employee and employer.

As noted, there is very limited established evidence-based research on customized employment as an intervention to improve the employment outcomes of individuals with disabilities, although anecdotal reports from early practitioners have indicated promise in its utility (e.g., Riesen, Morgan, \& Griffin, 2015). For example, Callahan, Griffin, and Hammis (2011) described the efforts of the Office of Disability Employment Policy, beginning in 2001, to provide a foundation for the concept of customized employment. These projects demonstrated a variety of strategies within the framework of customized employment, and many achieved some very positive employment outcomes (Elinson, Frey, Li, Palan, \& Horne, 2008). A review of the project descriptions clearly indicates that they were not designed to include research methodology where the results of control and experimental groups could be compared, a critical component of evidenced-based research. As a result, the descriptions of the strategies used in these projects do not lead to a cohesive, research-based compendium that could serve as the basis for an evidenced-based description of customized employment. The next step is the progression of research from practitioner descriptions of customized employment to a research-validated catalog of evidenced-based practices that can be consistently replicated. 
Future research. Evaluating efficacy and cost-benefit of customized employment is needed, especially for individuals with most significant disabilities who are at greatest risk to be excluded from supports needed to accomplish CIE. Efficacy research demonstrating the benefits of customized employment services on desired outcomes would send a clear message to policy makers, practitioners, and future researchers alike that CIE should be continued and expanded. Furthermore, investigation into how the business community customizes jobs and benefits from hiring individuals with disabilities in order to facilitate CIE outcomes is needed.

Fidelity scale development. Current efforts to develop a fidelity scale for customized employment offers the potential of allowing researchers to refine best practices within the field to ensure more consistent provision of quality services (Jorgensen Smith, 2017). In turn, this would help create incentives to reward practitioners who provide exemplary customized employment services with fidelity. Moreover, since WIOA has added customized employment as a component of supported employment and potential service option for VR recipients with disabilities, the development of measures that establish the quality and fidelity of these services is needed to quantify the cost-benefit for agencies, and ultimately, taxpayers. Further research is needed to provide evidence-based practices to form the necessary foundation, including a more comprehensive intervention package with well-developed and specific fidelity measures.

\section{Internships \& Work-based Learning}

One model shown to facilitate employment and successful post-school employment outcomes for students with disabilities is participation in internships prior to exiting high school. Internship experiences involve working at a host business for a fixed period of time to learn skills and to perform skills that benefit both the business and the intern (Daston, Riehle, Rutkowski, 2012). These work-based learning models are beginning to gain traction for students 
with disabilities and initial studies offer promising results for promoting employment after graduation (Mazzotti et al., 2016). Work experiences have long been associated with positive CIE outcomes (Test, Smith, \& Carter, 2014; Test et al., 2009). Additionally, participation in work experiences or vocational training while still in high school have consistently been found to be a predictor of postsecondary employment for students with disabilities (Wehman et al., 2014; Test et al., 2009).

One internship model, Project SEARCH, an employment training program for high school students with disabilities, has well documented success in the literature. In the SEARCH model, students rotate through three different internships during their last year of high school. Each rotation lasts from ten to twelve weeks. Important aspects of the SEARCH model are intensive job site training and minimal time spent in the classroom. Students spend the majority of internship hours learning and practicing job readiness and social skills in real settings rather than focusing on academic curriculum (Schall et al., 2015). In the SEARCH model, students are supported by both teachers and employment specialists to acquire job skills. Initial studies in the SEARCH model have demonstrated success in supporting students to gain employment postgraduation. Wehman and colleagues (2016), in a randomized controlled trial of Project SEARCH plus Autism Spectrum Disorder Supports (PS-ASD), showed that students with significant needs who participate in internships with job and behavioral supports are more likely to gain employment than students who do not receive these services. Other research has demonstrated an increased chance of postsecondary employment and job readiness through participation in SEARCH training (Muller \& VanGilder, 2014).

Direct, hands on work experiences prior to exiting high school enables students with disabilities to learn not only job skills but also to acquire the "soft skills" that greatly facilitate 
CIE (Wehman et al., 2016; Muller \& VanGilder, 2014). Soft skills, or workplace social skills, such as greeting coworkers, engaging in appropriate breakroom conversation, and making eye contact are important to workplace success (Morningstar, Lombardi, Fowler, \& Test, 2017). Engaging in work experiences prior to exiting high school is a double sided benefit. This also helps to build relationships with employers and allows for employers to get to know individuals with disabilities. It may also decrease stereotypes and concerns over hiring individuals with disabilities. While initial studies and research lend credence to providing work experiences and internship opportunities prior to exiting high school, additional research is needed on this practice in addition to the provision of technical support to education agencies to increasingly implement this practice.

While initial controlled trials have shown efficacy for internship models that provide specialized support and skill development for youth with I/DD, further research is needed to replicate these findings for different types of internship opportunities and employment fields for individuals with most significant disabilities. Furthermore, it remains to be discovered which specific factors in previously researched internship models directly contributed to increased CIE. Investigating these factors and establishing fidelity measures could provide schools without internship partnerships in place an opportunity to promote these experiences and build broader capacity to increase CIE nationwide.

\section{College \& Career Readiness}

Young adults with I/DD often share the same aspirations as other students without disabilities related to attending college and gaining skills needed to obtain employment. Unlike their peers without disabilities, students with I/DD have historically been excluded from attending college, through stringent entrance requirements and ineligibility for federal student aid 
programs. However, access to higher education is increasingly tied to critical outcomes, such as improved career prospects, for all students, regardless of disability status. In the years to come, some sort of college experience will be required for approximately two-thirds of jobs (Carnevale, Smith, \& Strohl, 2010). Yet transition-aged youth with ID have the lowest rates of postsecondary enrollment of any disability group (29\%), and that number drops to $7 \%$ when four-year college enrollment is specified (Newman et al., 2011). Furthermore, despite increases in the enrollment rates of students with disabilities, retention of student to degree completion remains a widespread issue (Getzel, 2008; Prohn, Kelley, \& Westling, 2018).

The Higher Education Opportunity Act (HEOA) of 2008 sought to increase opportunities for young adults with I/DD to participate in college in several ways. Federal grant funding was awarded to various demonstration sites, called Transition and Postsecondary Programs for Students with Intellectual Disability (TPSID). TPSID programs provide integrated college experiences at two-and-four year universities and colleges across the United States, focusing on academic, vocational, and independent living skills. HEOA also enabled students with I/DD access to some forms of federal financial assistance in postsecondary settings through enrollment in work study programs. Finally, HEOA established funding for a national coordinating center to oversee data collection and provide training and technical assistance to inclusive postsecondary education programs (Grigal, Hart, Smith, Domin, \& Weir, 2015).

What we know thus far from the relatively recent emergence of these postsecondary educational programs is that college experiences provide a viable and unique pathway to CIE (Grigal et al., 2015; Moore \& Schelling, 2015; Ross, Marcell, Williams, \& Carson, 2013) and that participation in postsecondary education significantly increases the odds of successful employment for students with I/DD (Grigal, Hart, \& Migliore, 2011). Additionally, transition- 
aged supported employees with ID who have postsecondary educational experience work more hours and earn higher wages across a wider range of occupations than youth with less education (Cimera, Thoma, Whittenburg, \& Ruhl, in press). We also know that several aspects of postsecondary educational programs for young adults with I/DD are particularly promising. Through inclusive academic coursework and sustained opportunities for social involvement on campus, college students with I/DD learn skills needed for employment success (Prohn \& Camden, 2017; Prohn et al., 2018; Thoma, 2013).

As the field moves forward, it will be important to identify how to expand both the number of inclusive college programs for students with I/DD and the number of students attending such programs. Program expansion will require secondary schools, state vocational rehabilitation agencies, community rehabilitation providers, and colleges and universities to collaborate in new and creative ways to develop and support new inclusive postsecondary educational programs. It will also require shifts in mindsets from viewing college as an experience reserved for a select few to thinking about college as a possibility for everyone, including individual with the most significant disabilities. Changes in thinking will also have to be accompanied by changes in secondary transition planning and practices, so that students with I/DD and their families have the information and experiences needed to evaluate if postsecondary education is the path they want to take. However, a significant barrier to increasing access to college for students with I/DD is funding. While investment in postsecondary educational programs for individuals with I/DD varies considerably between states and between specific programs, $61 \%$ of programs are financed at least in part through student tuition payments (Grigal, Hart, \& Weir, 2012). Moreover, as start-up grants and private contributions dissipate over time, programs focus more on tuition for funding. Ultimately, higher 
tuition rates may decrease access for students with limited financial means and may increase financial burdens on families (Plotner \& Marshall, 2015). This is an area that will require expertise and sustained planning to assist students and families in identifying braided funding sources - potentially through federal student aid programs, Social Security, vocational rehabilitation, and/or secondary schools - to finance college.

\section{Recommendations for Promoting Greater CIE for Persons with I/DD in the $2^{\text {st }}$ Century}

Since the early 1980s, progress has been made in helping persons with I/DD gain CIE, retain those jobs, and advance into other employment as well. There is an expectation by hundreds of thousands of parents of youth with I/DD that their sons and daughters should have a real job in the community for real pay and benefits. Segregation into special adult centers is increasingly no longer the first choice. In Table 2, we summarize facts that we now know about the CIE of persons with I/DD.

\section{INSERT TABLE 2 ABOUT HERE}

While the national statistics do not show the growth in competitive employment we would like to see, the fact is that now we have in the US between $20-25 \%$ of the country's persons with I/DD working competitively; more importantly in some states such as Vermont, Connecticut, Michigan, Oregon, Nebraska, Idaho, and Nevada, this percentage is much higher, rising above the $50 \%$ level of employment (Winsor et al., 2017). This is important because it demonstrates vocational capacity and suggests that perhaps in other states there are exogenous policies and practices (e.g., insufficient Medicaid Waiver support) that are interfering with higher quality outcomes. It is now established that many people with I/DD can work who never 
were thought able to before; this is a positive breakthrough that has emerged over the past three decades.

At the same time there is a small group of individuals with the most significant disabilities who are not getting the opportunity to work competitively, evidenced by an increasing national enrollment of adult day programs. Many professionals will point to a host of legitimate systems issues that are contributing to this problem. While this is true, the biggest barrier to advancing the employment of people with the most significant disabilities is the lack of strong community rehabilitation programs (CRPs). Most communities lack CRPs with staff that: 1) have community employment experience with this population, 2) believe in the employability of people with the most significant disabilities, 3) understand in the importance of employment for all, 4) have the capacity to deliver long term supports, and 5) have expertise working with employers. While the emergence of customized employment is a positive sign that help is on the way for this group; unfortunately, the amount of evidence based data on how to best implement customized employment still is lacking (Riesen et al., 2015).

Title I of the ADA and the actions of the DOJ, while changing legal policy and enforcement, have also influenced attitudes and behaviors. Furthermore, the Employment First initiative (Butterworth et al., 2017; Carter et al., 2017; Tucker et al., 2017) provides impetus for many states to change their policies by highlighting effective CIE practices within states, disseminating this information to a broader audience including individuals and parents. As a result, more and more of both individuals and parents with I/DD not "settling" for segregated centers or large group placements, but instead aggressively pushing for CIE.

After taking into account what is known about promoting CIE, there are a number of recommendations which we believe if implemented by the federal government and/or states, 
would lead to substantially improved outcomes. These recommendations are partially drawn from the Final Report of the U.S Department of Labor's Advisory Committee on Increasing Competitive Integrated Employment for Individuals with Disabilities (2017) as well as from a presentation from the 2016 TASH Conference (Wehman, 2016).

1. Enhancing Competencies of Employment Specialists. If individuals with the most significant disabilities are to become valued members of the workforce, then the field must invest in personnel training specifically designed for employment specialists. This group of professionals must possess a range of highly sophisticated skills such as business development, job analysis, discovery, systematic instruction, and positive behavioral supports. In addition, they must be able to coordinate employment services with a host of community service providers to include social service, vocational rehabilitation, transportation, education, and residential services. Two national organizations that have recognized the complexity of the Employment Specialist (ES) position and have developed a certification process for ES include: a) the Association of People Supporting Employment First (APSE) Certified Employment Support Professional certificate and b) the Association of Community Rehabilitation Educators' (ACRE) competency-based supported $/$ customized employment certificate. Both training programs are nationally recognized, but to date very few state VR programs require ES to possess one of these certifications. This must change if we are going to meet the employment needs of individuals with complex disabilities.

2. Evidence-based research. We need continued high quality research to identify evidence-based and emerging employment practices for youth with I/DD. Employment First projects hold promise in this area; however, these state efforts need for more strong intervention studies to evaluate their outcome. We are missing out on the impact of these wonderful efforts 
without more controlled research. The focus of some of this research should also be on the students while in school. All student experiences do not need to be the same, students should share the same or similar trajectory for experiences, but these experiences need to be individualized.

3. Research on CIE for those with the most significant disabilities. Despite significant success in the employment outcomes associated with the described pathways to CIE, there remains a dearth of literature on supporting those with the most significant physical, intellectual and behavioral disabilities to advance in CIE. There have been numerous anecdotal reports and clinical illustrations of success, so we know it is possible. However, this is not a group that has been highly focused upon in research according to our review. In order to accomplish this, interventions may need to be improved, staff better trained, and employer partnerships strengthened, or new technological advances employed. Our efforts at CIE outcome and enhancement are only as good as our success with of those with the greatest need, and we believe more research is required into how to promote CIE for these citizens.

4. School-community relationships. It is not the responsibility for schools to become community employment centers; however, it is the responsibility of the school to have an expectation that students can and will work. All student experiences do not need to be the same, students should share the same or similar trajectory for experiences, but these experiences need to be individualized. For this to occur there must be strong school-community relationships with ties to business and the vocational rehabilitation communities. There should be collaborative community-based experiences set up with businesses and vocational rehabilitation services with corresponding guidance documents on the roles and responsibility for each participating partner. Implementation of WIOA guidelines can help with this, but will need to be executed carefully. 
5. Provide transition and employment knowledge to family members. The field needs greater input from families as well as training programs run by families for families and dedicated to lifting the expectations of family members so they will pursue CIE (Gilson et al., 2017). Parents are a potential resource for promoting stronger levels of self-determination and better outcomes in CIE (Carter et al., 2013). School staff should provide student-specific information about transition and employment planning earlier in students' school-age years to equip parents with greater knowledge to make informed decisions (Gauthier-Boudreault, Couture, \& Gallagher, 2018).

Furthermore, while parents are acknowledged as a partner in IEP and transition planning, they are often overlooked for knowledge development. Developing the knowledge of family members about evidence-based practices for transition and predictors of postsecondary success in employment and other areas would empower them to promote the self-determination of their children throughout the transition process. It would seem that a natural home for such training would be the University Center's for Excellence in Developmental Disabilities (UCEDDs) that are networked across the country. With a stated mission of the full inclusion of all Americans with disabilities, this type of training would be a great fit.

6. Seamless transition to paid employment prior to graduation. Having a paid working experience prior to exiting high school is the number one predictor for youth with intellectual disabilities pursuing CIE after graduation (Certo \& Luecking, 2006). While all experiences need not be the same, there should be a shared trajectory for experiences. To make this happen employment goals must be written into the students IEP/ Transition Plan. The field must end the practice of developing transition plans that state the student will transition to a 
sheltered workshop or an adult day activity center. CIE must become a documented goal with strategies for accomplishment.

7. Inclusive social skills instruction. In today's workforce it is very important to have strong social skills, sometimes referred to as soft skills by the business community (Morningstar et al., 2017). Students with disabilities need not be educated separate from their peers in order to learn soft skills. It is possible to learn these skills in general education classes. Pulling students out and grouping them with other students with disabilities will not strengthen their communications skills or prepare them for CIE. More research is needed on the effectiveness of keeping students in general education classes versus separating them into groups of students with disabilities (all-inclusive settings vs. all segregated settings) in influencing outcomes postgraduation.

8. Lack of staff training at all levels. In stepping back to examine our progress, we inevitably return to the same problem. Senior human service managers do not see the positives as outweighing the costs involved in changing the system. Supervisors and direct service staff do not know how to conduct meaningful field assessments for competitive employment, employer engagement skills are weak, and systematic instruction often lacking — all of which leads to less intensely disabled clients being selected for work opportunities as opposed to those with greater support needs. There are numerous articles reflecting research on how to implement high quality competitive employment programs yet this knowledge is not being targeted to the people who need it the most, those providing services directly in the field on a day-to-day basis. Staff are often poorly paid, leading to frequent turnover and hence retraining needs.

\section{Conclusion}


Despite decades-long efforts to improve outcomes related to the competitive employment of people with I/DD, the reality is that integrated work remains elusive for many in this working age population. While pathways to successful CIE have been documented and show anecdotal success for many with even a high level of support needs, too many individuals continue to be removed from the competitive workforce into day programs and sheltered workshops. Recent policy developments through the reauthorization of WIOA, as well as DOJ efforts to enforce ADA regulations around segregated settings offer fresh hope of improving these rates through earlier intervention and interagency collaboration. 


\section{References}

Advisory Committee on Increasing Competitive Integrated Employment for Individuals with Disabilities. (2017) Department of Labor Final Report. Retrieved from https://www.dol.gov/odep/topics/pdf/ACICIEID_Final_Report_9-8-16.pdf

Association of People Supporting Employment First ([APSE]; 2017). Employment First Map. Retrieved from http://apse.org/employment-first/map/

Bellamy, T. (1988). Supported employment: A community implementation guide. Baltimore, MD: Brookes Publishing.

Bond, G. R., Drake, R. E., \& Becker, D. R. (2008). An update on randomized controlled trials of evidence-based supported employment. Psychiatric Rehabilitation Journal, 31(4), 280290.

Brown, L., Farrington, K., Suomi, J., \& Ziegler, M. (1999). Work-wage relationships and individuals with disabilities. Journal of Vocational Rehabilitation, 13(1), 5-13.

Butterworth, J. Christensen, J., Flippo, K. (2017). Partnerships in employment: Building strong coalitions to facilitate systems change for youth and young adults. Journal of Vocational Rehabilitation, 47(3), 265-276.

Callahan, M., Griffin, C., \& Hammis, D. (2011). Twenty years of employment for persons with significant disabilities: A retrospective. Journal of Vocational Rehabilitation, 35, 163172.

Carnevale, A.P., Smith, N., \& Strohl, J. (2010). Help wanted: Projections of jobs and education requirements through 2018. Retrieved from https://repository.library.georgetown.edu/bitstream/handle/10822/559303/FullReport.pdf $\underline{\text { ?sequence }=1}$ 
Carter, E. W., Austin, D., \& Trainor, A. A. (2011). Factors associated with the early work experiences of adolescents with severe disabilities. Intellectual and Developmental Disabilities, 49(4), 233-247.

Carter, E. W., Austin, D., \& Trainor, A. A. (2012). Predictors of postschool employment outcomes for young adults with severe disabilities. Journal Of Disability Policy Studies, 23(1), 50-63. doi:10.1177/1044207311414680

Carter, E. W., Lane, K. L., Cooney, M., Weir, K., Moss, C. K., \& Machalicek, W. (2013). Parent assessments of self-determination importance and performance for students with autism or intellectual disability. American Journal on Intellectual and Developmental Disabilities, 118(1), 16-31.

Carter, E. W., McMillan, E., Willis, W., \& TennesseeWorks Partnership. (2017). The TennesseeWorks Partnership: Elevating employment outcomes for people with intellectual and developmental disabilities. Journal of Vocational Rehabilitation, 47(3), 365-378.

Centers for Medicare and Medicaid Services. (2013). Fact Sheets. Retrieved on December 19, 2017 from https://www.cms.gov/Newsroom/MediaReleaseDatabase/Fact-sheets/2013Fact-sheets.html.

Certo, N. J., \& Luecking, R. G. (2006). Service integration and school to work transition: Customized employment as an outcome for youth with significant disabilities. Journal of Applied Rehabilitation Counseling, 37(4), 29-35.

Chan, F., Strauser, D., Maher, P., Lee, E.-J., Jones, R., \& Johnson, E. T. (2010). Demandside factors related to employmentof people with disabilities: A survey of employers in 
the midwest region of the United States. Journal of Occupational Rehabilitation, 20(4), 412-419.

Christensen, J. J., Richardson, K., \& Hetherington, S. (2017). New York State Partnerships in Employment. Journal of Vocational Rehabilitation, 47(3), 351-363.

Cimera, R. E. (2012). The economics of supported employment: What new data tell us. Journal of Vocational Rehabilitation, 37(2), 109-117.

Cimera, R.E., Thoma, C.A., Whittenburg, H.N., \& Ruhl, A.N. (in press). Is getting a postsecondary education a good investment for supported employee with intellectual disabilities and taxpayers. Inclusion.

Daston, M., Riehle, E., Rutkowski, S. (2012). High School Transition That works! Lessons Learned from Project SEARCH. Baltimore, MD: Brookes Publishing.

Department of Justice (2014, April 8). Department of Justice reaches landmark Americans with Disabilities Act settlement agreement with Rhode Island. [Press release]. Retrieved from https://www.justice.gov/opa/pr/department-justice-reaches-landmark-americansdisabilities-act-settlement-agreement-rhode

Elinson, L \& Frey, W.D. \& Li, T \& Palan, M.A. \& Horne, R.L.. (2008). Evaluation of customized employment in building the capacity of the workforce development system. Journal of Vocational Rehabilitation, 28(3), 141-158.

Gauthier-Boudreault, C., Couture, M., \& Gallagher, F. (2018). How to facilitate transition to adulthood? Innovative solutions from parents of young adults with profound intellectual disability. Journal Of Applied Research In Intellectual Disabilities, 31, 215-223. 
Getzel, E.E. (2008). Addressing the persistence and retention of students with disabilities in higher education: Incorporating key strategies and supports on campus. Exceptionality: A Special Education Journal, 16(4), 207-219.

Gilson, C. B., Carter, E. W., Bumble, J. L., \& McMillan, E. D. (2018). Family Perspectives on Integrated Employment for Adults with Intellectual and Developmental Disabilities. Research \& Practice For Persons With Severe Disabilities, 43(1), 20-37.

Gilson, C. B., Bethune, L. K., Carter, E. W., \& McMillan, E. D. (2017). Informing and equipping parents of people with intellectual and developmental disabilities. Intellectual and Developmental Disabilities, 55(5), 347-360.

Griffin, C., Hammis, D., Geary, T., \& Sullivan, M. (2008). Customized employment: Where we are; where we're headed. Journal of Vocational Rehabilitation, 28(3), 135-139.

Grigal, M., Hart, D., \& Migliore, A. (2011). Comparing the transition planning, postsecondary education and employment outcomes of students with intellectual and other disabilities. Career Development for Exceptional Individuals, 34(1), 4-17.

Grigal, M., Hart, D., Smith, F.A., Domin, D., Sulewski, J., \& Weir, K. (2015). Think College National Coordinating Center: Annual report on the transition and postsecondary programs for students with intellectual disabilities (2012-2013)-executive summary. Boston: Institute for Community Inclusion, University of Massachusetts Boston. Grigal, M., Hart, D., \& Weir, C. (2012). A survey of postsecondary education programs for students with intellectual disabilities in the United States. Journal of Policy and Practice in Intellectual Disabilities, 9(4), 223-233.

Hiersteiner, D., Bershadsky, J., Bonardi, A., \& Butterworth, J. (2016). Working in the community: The status and outcomes of people with intellectual and developmental 
disabilities in integrated employment--Update 2. NCI Data Brief, April 2016. Cambridge, MA: Human Services Research Institute.

Inge, K., Graham, C., Brooks-Lane, N., Wehman, P., \& Griffin, C. (2018). Defining customized employment as an evidence-based practice: The results of a focus group study. Journal of Vocational Rehabilitation, 48(2).

Jorgensen Smith, T. (2017). Achieving Competitive Customized Employment Though Specialized Services: Benchmarks of Quality Checklist.

Mank, D., Cioffi, A., \& Yovanoff, P. (1998). Employment outcomes for people with severe disabilities: Opportunities for improvement. Mental Retardation, 36(3), 205-216.

Mazzotti, V. L., Rowe, D. A., Sinclair, J., Poppen, M., Woods, W. E., \& Shearer, M. L. (2016). Predictors of Post-School Success: A Systematic Review of NLTS2 Secondary Analyses. Career Development and Transition for Exceptional Individuals, 39(4), 196-215.

Migliore, A., Grossi, T., Mank, D., \& Rogan, P. (2008). Why do adults with intellectual disabilities work in sheltered workshops? Journal of Vocational Rehabilitation, 28(1), 29-40.

Migliore, A., Timmons, J., Butterworth, J., \& Lugas, J. (2012). Predictors of employment and postsecondary education of youth with autism. Rehabilitation Counseling Bulletin, 55(3), 176-184.

Morningstar, M. E., Lombardi, A., Fowler, C. H., \& Test, D. W. (2017). A College and Career Readiness Framework for Secondary Students With Disabilities. Career Development and Transition for Exceptional Individuals, 40(2), 79-91. 
Moore, E.J., \& Schelling, A. (2015). Postsecondary inclusion for individuals with an intellectual disability and its effects on employment. Journal of Intellectual Disabilities, 19(2), 130148.

Muller, E., \& VanGilder, R. (2014). The relationship between participation in Project SEARCH and job readiness and employment for young adults with disabilities. Journal of Vocational Rehabilitation, 40, 15-26.

Newman, L., Wagner, M., Knokey, A.-M., Marder, C., Nagle, K., Shaver, D., Wei, X., with Cameto, R., Contreras, E., Ferguson, K., Greene, S., and Schwarting, M. (2011). The post-high school outcomes of young adults with disabilities up to 8 years after high school. A report from the National Longitudinal Transition Study-2 (NLTS2) (NCSER 2011-3005). Menlo Park, CA: SRI International.

Office of Disability Employment Policy (2005). Customized employment: Practical solutions for employment success. Retrieved Jan 23, 2018 from https://www.dol.gov/odep/categories/workforce/CustomizedEmployment/practical/index. $\underline{\text { htm }}$

Oregon Department of Human Services (2018). Lane v. Brown Settlement Data Report. Retrieved March 26, 2018 from http://www.oregon.gov/DHS/EMPLOYMENT/EMPLOYMENTFIRST/Documents/Lane\%20v\%20Brown\%20Semi-annual\%20Report\%202-28-17.pdf

Ottomanelli, L., Goetz, L. L., Suris, A., McGeough, C., Sinnott, P. L., Toscano, R., \& Holmes, S. A. (2012). Effectiveness of supported employment for veterans with spinal cord injuries: Results from a randomized multisite study. Archives of physical medicine and rehabilitation, 93(5), 740-747. 
Plotner, A.J., \& Marshall, K.J. (2015). Postsecondary education programs for students with an intellectual disability: Facilitators and barriers to implementation. Intellectual and Developmental Disabilities, 53(1), 58-69.

Prohn, S. M., \& Camden, J. A. (2017, November). The development of a milestone payment partnership for postsecondary education. Presented at The State of the Art Conference on Postsecondary Education and Individuals with Intellectual Disabilities, Syracuse, NY.

Prohn, S. M., Kelley, K. R., \& Westling, D. L. (2018). Students with intellectual disability going to college: What are the outcomes? A pilot study. Journal of Vocational Rehabilitation, 48(1), 127-132. https://doi.org/10.3233/JVR-170920

Riesen, T., Morgan, R. L., \& Griffin, C. (2015). Customized employment: A review of the literature. Journal of Vocational Rehabilitation, 43(3), 183-193.

Ross, J., Marcell, J., Williams, P., \& Carson, D. (2013). Postsecondary education, employment, and independent living outcomes of persons with autism and intellectual disability. Journal of Postsecondary Education and Disability, 26(4), 337-351.

Rusch, F. R., \& Braddock, D. (2004). Adult day programs versus supported employment (19882002): Spending and service practices of mental retardation and developmental disabilities state agencies. Research and Practice for Persons with Severe Disabilities (RPSD), 29(4), 237-242.

Schall, C., Wehman, P., Brooke, V., Graham, C., McDonough, J., Brooke, A., Ham, W., \& Rounds, R. (2015). Employment Interventions for Individuals with ASD: The Relative Efficacy of Supported Employment With or Without Prior Project SEARCH Training. Journal of Autism and Developmental Disorders, 45(12), 3990-4001. 
Siperstein, G. N., Heyman, M., \& Stokes, J. E. (2014). Pathways to employment: A national survey of adults with intellectual disabilities. Journal Of Vocational Rehabilitation, 41(3), 165-178. doi:10.3233/JVR-140711

Siperstein, G. N., Parker, R. C., \& Drascher, M. (2013). National snapshot of adults with intellectual disabilities in the labor force. Journal of Vocational Rehabilitation, 39(3), 157-165. doi:10.3233/JVR-130658

Smith, T. J., Dillahunt-Aspillaga, C., \& Kenney, C. (2015). Integrating customized employment practices within the vocational rehabilitation system. Journal of Vocational Rehabilitation, 42(3), 201-208.

Test, D., Mazzotti, V., Mustian, A., Fowler, C., Kortering, L., \& Kohler, P. (2009. EvidenceBased Secondary Transition Predictors for Improving Postschool Outcomes for Students with Disabilities. Career Development for Exceptional Individuals, 32(3), 160-181.

Test, D. W., Smith, L. E., \& Carter, E. W. (2014). Equipping Youth With Autism Spectrum Disorders for Adulthood: Promoting Rigor, Relevance, and Relationships. Remedial \& Special Education, 35(2), 80-90.

Thoma, C.A. (2013). Postsecondary education for students with intellectual disability: Complex layers. Journal of Postsecondary Education and Disability, 26, 285-302.

Tucker, K., Feng, H., Gruman, C., \& Crossen, L. (2017). Improving competitive integrated employment for youth and young adults with disabilities: Findings from an evaluation of eight Partnerships in Employment Systems Change Projects. Journal of Vocational Rehabilitation, 47(3), 277-294.

Wehman, P. (1981). Competitive employment: New horizons for severely disabled individuals. Baltimore, MD: Paul H. Brookes Publishers. 
Wehman P. (2011). Employment for persons with disabilities: where are we now and where do we need to go? Journal of Vocational Rehabilitation. 35(3).145-51.

Wehman, P. (2016; November). Supported Employment for The Most Disenfranchised and Challenged From Church Basements to the Department of Justice: Where We Are and Where We Need to Go. Paper presented at 2016 TASH Conference, St. Louis, MO.

Wehman, P., Brooke, V., Brooke, A., Ham, W., Schall, C., McDonough, J., Lau, S., Seward, H., \& Avellone, L. (2016). Employment for adults with autism spectrum disorders: A retrospective review of a customized employment approach. Research in Developmental Disabilities, 53(54), 61-72.

Wehman, P., Chan, F., Ditchman, N., \& Kang, H. J. (2014). Effect of supported employment on vocational rehabilitation outcomes of transition-age youth with intellectual and developmental disabilities: A case control study. Intellectual and Developmental Disabilities, 52(4), 296-310.

Wehman, P., Lau, S., Molinelli, A., Brooke, V., Thompson, K., Moore, C., \& West, M. (2012). Supported employment for young adults with autism spectrum disorder: Preliminary data. Research and Practice for Persons with Severe Disabilities, 37(3), 160-169.

Wehman, P., Revell, W. G., \& Brooke, V. (2003). Competitive Employment Has It Become the “First Choice” Yet?. Journal of Disability Policy Studies, 14(3), 163-173.

Wehman, P., Schall, C., McDonough, J., Kregel, J., Brooke, V., Molinelli, A., \& Thiss, W. (2014). Competitive Employment for Youth with Autism Spectrum Disorders: Early Results from a Randomized Clinical Trial. Journal Of Autism \& Developmental Disorders, 44(3), 487-500. doi:10.1007/s10803-013-1892-x 
Wehman, P., Targett, P., West, M., \& Kregel, J. (2005). Productive work and employment for persons with traumatic brain injury: What have we learned after 20 years?. The Journal of Head Trauma Rehabilitation, 20(2), 115-127.

Winsor, J., Timmons, J., Butterworth, J., Shepard, J., Landa, C., Smith, F., Domin, D., Migliore, A., Bose, J., Landim, L. (2017). StateData: The national report on employment services and outcomes. Boston, MA: University of Massachusetts Boston, Institute for Community Inclusion.

Workforce Innovation and Opportunities Act of 2014, PL 113-128, STAT. 1634. 
Table 1

Customized Employment Job Development Methods and Descriptions.

\begin{tabular}{ll}
\hline Implementation Step & Description \\
\hline Job Carving & - Using some elements of a job description, but not all \\
& responsibilities \\
Job Negotiation & Combining tasks from multiple job descriptions within a \\
& business into a new job description. \\
Job Creation & New job description is created from unmet business \\
& needs identified during discussions between employer \\
Self-employment & and employment specialist. \\
& without the help of paid (e.g., service agencies) or \\
& unpaid (e.g., family members) support.
\end{tabular}


Table 2

What We Know About Employment for Individuals with I/DD.

1. A significant majority of persons can work competitively with appropriate workplace and family supports.

2. Those with the most significant disabilities are still not participating in the pathways to employment.

3. Supported employment currently has stronger evidence of CIE efficacy than internships, customized employment and college and career readiness models where initial research evidence is still emerging.

4. Employers are increasingly aware of the positive contributions and work capacity of persons with ID/DD these findings are more anecdotal than evidence based.

5. Persons with disabilities prefer competitive employment to sheltered employment or segregated day care centers

6. Family support is critical and more and more families are promoting competitive employment as a first choice.

7. Policy practices from Congress through the ADA and WIOA and from the Department of Justice and Center for Medicare Services are making a difference but it is a slow process.

8. The number of persons entering CIE from day programs has stagnated.

9. Supported employment is a more cost efficient approach than sheltered employment.

10. None of the models have sufficiently well trained personnel to provide the 
fidelity of implementation that is required to achieve long-term CIE. 